\title{
Path analysis of Wenzhou fashion city localization design in industry chain perspective
}

\author{
Xia Zhijie \\ Institute of economic and trade, Zhejiang Industry\&TradeVocational College, Fudong \\ Street,Wenzhou, China
}

Keywords: Industry chain;Value chain;Fashion industry;Light industry;Smart products era

\begin{abstract}
Wenzhou as the development of light industry take the upper hand in manufacturing industry with superior transportation、 merchants resources, however, In the era of new smart products, the rise of human cost, environmental cost pay become the driving force for wenzhou improve development of the industry chain. In this way the fashion industry development is the valuable conclusions after years of practice, is an important force for Wenzhou second industry such as shoes、clothes industry's smoothly transformation in high-end custom transformation, high added value, is the important point of wenzhou combining tradition and fashion culture. Give full play to the design strength in the industry is the backbone in rising Wenzhou's industrial clusters competitiveness, the most important factors to cultivate support strength of the fashion industry.
\end{abstract}

Wenzhou, also referred to as "Ou", is known as one of the three major central cities in Zhejiang, the home to the private economic development of China, as well as the pacesetter of the opening up and reform. At present, Wenzhou economy has experienced a change from the average high growth rate at more than $10 \%$, to the moderate and high growth in recent years. Subject to the new economy pattern and trend, Wenzhou is at the stage of economic restructuring and becomes more aware of the upgrading and efficiency of its economic development, compared with the single assessment standard of its economic growth rate. The previous development path that relies on "Three Low" (low labor cost, low-end products, and low-price competition) has come to an end, Wenzhou has to vigorously support the strategic hi-tech industries and tap its new growth point on the way to sustainable economic development. On the one hand, the development of fashion industry will lead to the transformation of light industry, and on the other hand, it will evolve as the development feature of Wenzhou to boost the revival of Wenzhou.

\section{Fashion Industry and Its Value Chain}

\subsection{Intension of fashion industry}

Fashion industry is based on the rising consumption levels of citizens and their aesthetic needs and consumption concepts for higher standard of consumption, life and culture. Fashion industry 
mainly involves three hierarchical layers: the core layer, the expansion layer, and the extension layer. The core layer is mainly about the individual beauty and decoration, e.g.: clothes, shoes and hats, hairdressing and beauty; the expansion layer contains a series of products or industries used for the beauty or decoration of the small environment where individuals live, e.g.: household items, decoration; the extension layer mainly involves the social environment where men live in harmony, e.g.: building fashion blocks or even fashion cities.

Fashion industry is an emerging industry operating a new commercial activity that creatively and productively integrates the second and third industry. In addition to the concept of modern advanced manufacturing industry, it is an organism that integrates the modern aesthetics and the traditional culture. Fashion industry takes the form of the clustering scale and effect, rather than a specific single industry.

\subsection{Value Chain of Fashion Industry}

A fashion enterprise is closely associated with the related enterprises and industries, which mainly focuses on fashion products, ensures the maximization of product added-value, and establishes the value chain network where fashion value, information and capital can properly and smoothly flow as the value chain of fashion industry.

This value chain is mainly composed of R\&D-Design-Processing \&Manufacturing-Display, and Experience-Sales-Brand Building. Based on the creativity and fashion orientation of fashion industry, R\&D design is not only an improvement on product, but also a critical component of value enhancement. As described in Shi Zhenrong's "Smiling Curve", the added-value of industry chain resembles a smiling curve, more added-values are reflected in design and sales at the ends of the value chain, while the added-value of manufacturing in the middle part is the lowest, as shown in FIG.1.

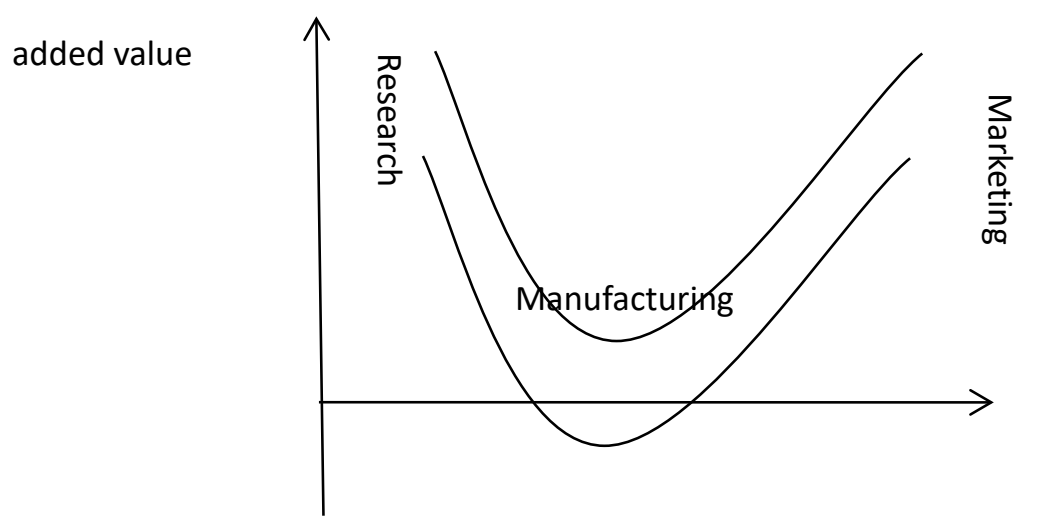

FIG.1 Smiling Curve

According to the theory of Smiling Curve, the increase of the high added-value of a product can forwardly strengthen its R\&D design, and backwardly strengthen the brand operation and marketing channel management of the enterprise. For example, the technicians and developers of R\&D centers in Wenzhou-based shoes manufacturers like Aokang and Red Dragonfly are more than 400-500, and they have also appointed Italian shoe masters and designers to supervise the R\&D in Wenzhou. From the brand operation and marketing channel management, these manufacturers have established distribution channels by opening exclusive stores, shops and shoe malls across the nation ${ }^{[1]}$. So far, the ratio of creative fashion industry to Wenzhou's GDP has been 
about $4 \%$ and there are enormous potentials of growth in future. However, the primary concern is how to integrate a large number of Wenzhou industries into a whole and complete fashion industry chain in alignment with the current time and society.

\section{Significance of the development of fashion industry in Wenzhou}

Since the 1980s, Wenzhou has heralded the reform of national market economy by establishing light industry as the pillar industry, but in the new age featuring a new economic model, this traditional extensive development model cannot help companies and enterprises foster a good development pattern. The impact of financial crisis has rapidly exposed its deficiencies in an unexpected way. Wenzhou's decision of "developing fashion industry, building the city of fashion" is in line with the enhancement of core competitiveness, the living needs, and the current trend, on its road to the transformation and upgrading of light industry and the transformation development.

\subsection{Boost the labor division and cooperation of the second, third industry, enhance the overall core competitiveness of the industry}

It is easily understood that the creation of fashion industry means a substantial change for enterprises, as long as we can get out of the misconception of building a fashion industry by just increasing some cultural or scientific elements in any product, because $R \& D$ design leads the development of fashion industry, and the previous development model of Wenzhou-based private enterprises, featuring low labor cost, low-end products, and low-price competition, has been grimly challenged. To build a fashion brand, the priority is to establish a good system for fashion industry. In addition to the low-value-added manufacturing process, Wenzhou has to drive the innovation on fashion industry chains such as R\&D design, logistics supply, marketing, information and professional service, finance and venture capital investment, management consulting and HR resource development, build a brand-new operation and management model, and take the lead to form the core competitiveness of industry specialization and differentiation ${ }^{[2]}$.

\subsection{Facilitate the upgrading of consumption structure and meet the hierarchical needs of consumers}

In 2016, the total retail sales of social consumer goods in Wenzhou amounted to RMB 300.6 billion, with a growth of $12.3 \%$, or $1.3 \%$ higher than the average level of Zhejiang, ranking the first place in Zhejiang. At present, the enormous potentials of economic development are indicated in the steady growth of the consumer market scale, accelerated upgrading of structure, and more contributions from consumption to the economic growth. The consumption upgrading has stimulated the service consumption as a "new favorite" among many consumers [3]. In 2016, Wenzhou "Wuma" Fashion Consumption Index shows that the overall fashion awareness and consumer quality of Wenzhou citizens are increasingly enhanced, along with diversified consumption patterns and increasing purchase power.

\section{Base and Advantages for the Development of Fashion Industry in Wenzhou}

\subsection{Established base of the light industry}

Light industry is more likely to play a critical role in the business or city transformation because of its flexibility, especially as a dominant part of fashion in the garment industry, and maintains the central presence in the network of fashion industry. In this sense, fashion industry emerges from the 
garment-oriented light industry. Wenzhou light industry is a feature and pillar component of the industrial structure, some industries are the national leaders in respect of the production scale, equipment level, associated system, market share and brand image, and maintain certain competitiveness in international market ${ }^{[4]}$. Thisprovides the strongest support for the fashion industry of Wenzhou. Take Wenzhou garment industry for example, nearly half of the TOP 10 men's garment brands place orders to Wenzhou manufacturers, indicating that the garment brands are very competitive in international arena.

\subsection{Extensive information network of Wenzhou businessmen}

Wenzhou businessmen are Chinese local merchant group as famous as Anhui, Shanxi, Shanghai and Guangdong businessmen. They are famous across the world for strong mobilization of capital, acute business sense, and quicker access to business opportunities, also referred to as "Oriental Jews".

Wenzhou businessmen are the precious wealth of Wenzhou, they like adventures and millions of Wenzhou businessmen are distributed in more than 150 countries and regions nationwide and across the world. They prefer holding together as a group, so that a business network covering the nation and connecting the world has been established; in 2016, Wenzhou GDP was among the TOP 3 in Zhejiang Province, which is mainly attributed to the innovative, venturing and progressive spirit of Wenzhou citizens; Wenzhou businessmen always set the pace of current trend and are regarded as trailblazers. In this age of internet and information economy, most Wenzhou businessmen could exploit the internet thinking, big data, and cloud computing, or other concepts and technologies to seize the good opportunity of resource integration in the internet age, and make innovation on the new internet-based business model. Recently, as inspired by the "Return of Zhejiang Businessmen” program implemented in Zhejiang, Wenzhou businessmen who are conducting business in other places actively respond to the Municipal Party Committee and Municipal Government to boost the integrated economic development of Wenzhou.

\subsection{Foster the awareness of fashion consumption}

In 2014, Wenzhou Municipal Party Committee issued "Decision on Developing the Fashion Industry and Building the City of Fashion" explicitly states that fashion industry is the road to industry and city transformation, Wenzhou has been also vigorously boosting the development of fashion consumption, stimulating the domestic demand to promote consumption, and driving the industry transformation and upgrading. By the end of 2016, 6 city complexes, 2 large fashion-oriented commerce and trade centers, more than 2 provincial and state-level feature commercial streets, and Qidu City Complex, Aomall International Shopping Center, Atlantic Intime Center, Wenzhou Jiaoyun International Taobao Mall, Longwan E-commerce Building and other fashion consumption venues have been built, the total retail sales of social consumer goods exceed RMB 300 billion, in which the sales volume of fashion consumer goods hit RMB 47 billion. By now, the fashion consumption has been booming that it was before, and the fashion awareness has been enhanced as well.

\subsection{Well-established urban infrastructure}

According to the 2015 population sampling survey, the permanent population of Wenzhou ranks the first place in Zhejiang, in 9.11 million, with a huge group of fashion consumption. Wenzhou is a central city of politics, economy and culture in the south of Zhejiang and in the north of Fujian. It was once a major port during the period of the Northern Song Dynasty, now remains at the hub of 
cargoes transport between the south part of Zhejiang and the north part of Fujian. Wenzhou was previously subject to the limitation of city areas, but now it has an access to more development spaces and regional resources by reclaiming tidelands. In addition, Wenzhou also has an accessible dimensional traffic network, such as harbor, railway, expressway, international airport. With respect to the fashion leadership, Wenzhou has held China (Wenzhou) International Fashion Consumption Expo since 2013, so as to create a good atmosphere of fashion.

\section{Problems of the Fashion Industry Value Chain of Wenzhou}

\section{1. $R \& D$ design: Lack of leading designers in a true sense}

As high added-value mainly originates from design and marketing, the injection of design forces into light industry will be very effective for the improvement of product fashion nature. Among the Wenzhou-based colleges, Wenzhou University has a dominant presence, and some vocational colleges such as Zhejiang Industry \& Trade Vocational College, Wenzhou Vocational \& Technical College, Zhejiang DongFang Vocational and Technical College are established as the talent development base. Such collages run design schools and offer industrial design, shoes \& garment design, visual communication design, advertising design and other programs specific for Wenzhou pillar industries, so as to add an innovation gene into traditional industries in Wenzhou and provide talent and technology support for the main development platform of its urban fashion industry.

However, the conflict between the output of design talents and the business demand for such talents tends to be prominent, the design competence, cultural sense and fashion degree of the design graduates are questioned, so that they will not be assigned with major tasks after graduation. For the problems of Wenzhou colleges, they are very sensitive to the market demand and their talent development programs are adjusted in line with the market demand. Wenzhou design subjects mainly offer specialized talents for the market and manufacturing demand of local enterprises and industries, also referred to as "artistic-industrial talents". These design talents are enough for the simple production in enterprises or factories, for example, Footwear Design in Wenzhou University focuses on the footwear industry as the dominant part of Wenzhou light industry, engages a collaborative talent program with Aokang, Red Dragonfly and Daphne, most graduates specializing in this subject will work on the design of samples and are not regarded as assistant designers in the designers' hierarchy involving design director, chief designer, designer and assistant designer. This talent orientation is far away from the professional demand from fashion industry on fashion sensitivity, independent design skills and efficient occupational capabilities. Thus, the design stage of many fashion industries needs to introduce nonlocal even foreign designers, which may significantly increase the design cost. Furthermore, the drainage of design talents will deprive of the design style and to the detriment of the long-term style formation. In this concern, it will be prioritized and urgent to develop local senior design talents in Wenzhou.

\subsection{Building of the fashion brand: The strategic awareness of business brand development should be enhanced}

According to the survey of China high-end fashion consumption power, Wenzhou is the dominant participant among prefecture-level cities across the nation in terms of the keen interests for the consumption of luxury goods, but the development level of Wenzhou fashion industry should be elevated to meet the needs of local citizens. Comparatively, the influence of Wenzhou fashion brands is increasing and the number of its registered fashion brands is among the leaders of similar cities across the nation. According to the statistics, as of 2014, Wenzhou had 38 China Top Brands, 58 China Famous Trademarks (administrative identification), 232 Zhejiang Top Brands, 
473 Wenzhou Top Brands, and 10 Geographical Indication Products; in January to November 2015, the online sales volume reached RMB 79.38 billion, with a YoY increase of $51.35 \%{ }^{[5]}$. In Wenzhou, the footwear industry represented by Aokang, Red Dragonfly and Saint Angelo, and the garment industry represented by Sharmoon, have pooled their efforts to create a new market featuring high-end customized service, while some brick-and-mortar enterprises represented by Semir and Metersbonwe are subject to enormous challenges from online shopping. Middle and high-end enterprises cannot form a fashion network chain in close connection, and especially it would be difficult for a few enterprises and industries to lead the idea of building Wenzhou as the city of fashion brands. In addition to the influence of other domestic middle and high-end fashion industries, Wenzhou fashion industry is subject to the influence of some foreign high-end brands. Wenzhou people have a strong awareness of brand and tend to highly recognize the foreign brands, leading to the growth of purchase agency industry. However, they may have no idea that many luxury brands such as Armani, Versace or Gucci collaborate with Wenzhou local enterprises and place orders to Wenzhou garment makers, only all high added-values are produced from the brands instead of Wenzhou manufacturing phase. Along with the emergence of market segmentation and individualization, Wenzhou enterprises have to build a road with typical local characteristics if they want to get on their own roads. Generally, the proprietary brand awareness of Wenzhou light industry is not well-established, so that Wenzhou light products are redirected to the domestic low or middle-end market, rather than the high-end market.

\subsection{The development of fashion industrial parks remains at the initial stage}

Wenzhou carries out the colleges-based research and innovation program industrial parks to drive the R\&D strength, implements "suppressing the second industry and developing the third industry" $1+X$ policy among old factories in urban areas, engages in the renewal of "old residential areas, old factories, urban villages, demolition of illegal construction" for the renewal programs of old factories, and has establishes several feature creative culture industrial parks, such as automobile sales, electronic information and innovation \& creativity. These creative parks intend to form the service industry agglomeration of Wenzhou S\&T innovation and creative culture, guide Wenzhou to be design-oriented, promote the integration between traditional industries and fashion, the second and third industry, and facilitate the transformation of production and manufacturing industries to the high-end customized comprehensive design service industry. In addition, these parks also cultivate creative culture talents in collaboration with colleges, for example, in 2015, Wenzhou Municipal Party Committee Propaganda Department, Wenzhou Municipal Culture, Radio, Film and Television Press and Publication Bureau, and Zhejiang Industry \& Trade Vocational College co-built the Wenzhou Cultural Creative College, in an attempt to cultivate creative talents depending on the domestic and foreign situation of culture industry and the local demand of creative culture development.

Some old factories take a new look after renewal, infused with food, fashion design industry, the industrial glory is transformed to serve the creative wisdom, these old factories recalling our past memory take a new look after addition of fashion elements, blended with food, film and fashion design industry, the industrial glory half a century ago has been converted into fashionable and intelligent creative elements. ${ }^{[6]}$ However, the emergence of creative parks also leads to some problems: some creative culture-oriented parks become the gathering place of restaurants, or it is difficult to form an industry chain in these parks. To simply put it, with the body of a creative culture park but deprived of its soul.

In Wenzhou, most creative culture parks remain at the initial stage and there is no mature business model. To sustain the long-term development, they must identify their own feature 
orientations in the market, actively explore the business model, infuse more creative elements depending on different resources, and attract creative design talents to establish a real creative base for fashion.

\subsection{Define objective, plan, and establish an accountability mechanism}

The construction of fashion industry is not completed immediately, but rather needs to define short, medium and long-term goal, adhere to the building of the city of fashion. Some personnel changes in the local government often discontinue the implementation of policies, which may require the government to develop the development strategies for different periods and enforce these strategies steadily, with the central objective of construction; the operating cost for fashion industry is higher, and there is always a lack of working capital in investment-return chain because it is not a mass production but oriented at customized service, which may require the government to vigorously support the living "soil" for fashion industry, for instance, lease the creative park to creative enterprises at a preferential price lower than the market price, or provide other subsidies; in case of capital shortage, the government or bank may at its own discretion offer a policy support; lastly, fashion industry should be closely associated with design, although designers highlight the creative works, once some products of fashion industry become best-sellers, they will be likely to be copied or imitated, which indicates that the intellectual protection is insufficient. This calls the need for the enactment of some applicable laws and regulations to counter again some infringement acts and protect the creative design works.

\section{Conclusion}

Wenzhou creative industry can be dated back to 2006, by now, great achievements have been made in 9 industries: advertising, handicrafts, fashion design, film and audiovisual products, music, performing arts, publications, software and computer service, television and radio, along with the construction of several creative culture parks: Zhejiang Creative Park, Wenzhou Creative Arts and Crafts Park, Honglian Creative Culture Park, Lucheng E-commerce Industry Park, Wisdom Valley, Dongou Think Tank Creative Industry Park, as well as Wenzhou Municipal Creative Culture Park located in in Wenzhou University Oujiang College ${ }^{[7]}$. In addition, Wenzhou fashion industry also faces a lot of concerns with respect to its development; 1 . Although the light industry has a strong base, the connection between different industries is weak, the maximization of resource value is subject to some challenges, the fashion development of light industry should exploit designs and creative ideas to fulfill the high added-value of products, integrate the second and third industry, and optimize the value chains of fashion industry; 2. As a strong vehicle of fashion industry, the fashion culture commercial streets have gained substantial progress with the support of Wenzhou Municipal Government, but the degree of innovation should be properly gripped, the development of Wenzhou creative parks remains at the initial stage, the subsequent efforts will be made to identify more fashion elements, introduce excellent design talents to lead the high-end fashion consumption, hold fashion summits to focus on the domestic and foreign fashion elements, pool efforts to build Wenzhou as the city of fashion where the atmosphere of fashion consumption is intensive, the fashion brands are numerous, and the fashion environment is comfortable.

\section{References}

[1] Research on the upgrading of Wenzhou footwear agglomeration based on global value chain[J]. Journal of International Trade, 2006.

[2] Research Report of China Fashion Industry [M]. Beijing: Economy \& Management Publishing House, 2012. 
[3] QiuHaifeng. China economy potentials highlighted by hot consumption [J]. People’s Daily, 2017.

[4] Chen Yixin. Developing the fashion industry, building the capital of fashion [J]. Policy Outlook, 2014.

[5] Jiang Yiyi. Serious spillover of Wenzhou high-end fashion consumption, low recognition of domestic brands [J]. Wenzhou Economic Daily, 2015.

[6] Wenzhou Daily. Slow-paced urban fashion life led by the creative culture parks [J]. Wenzhou Daily, 2017.

[7] Ye Dandan. On the development path of Wenzhou creative culture industry [J].Northern Economy, 2014

\section{About Author:}

Name: Xia Zhijie; Organization: Zhejiang Industry \& Trade Vocational College; Professional Title:

Lecturer; Capacity: Art Teacher for E-commerce; Diploma: Master Degree; Contact: 15869611021、 695020857@qq.com 